\title{
Characteristics of Linerboard and Corrugated Medium Paper Made from Durian Rinds Chemi-mechanical Pulp
}

\author{
Shaiful Rizal Masrol ${ }^{1,2, a}$, Mohd Halim Irwan Ibrahim ${ }^{2,3}$, Sharmiza Adnan ${ }^{4}$, Muhammad Syauqi Asyraf \\ Ahmad Tajudin ${ }^{3}$, Radhi Abdul Raub ${ }^{3}$, Siti Nurul Aqma Abdul Razak ${ }^{3}$ and Siti Nur Faeza Md Zain ${ }^{3}$ \\ ${ }^{1}$ Faculty of Engineering Technology, Universiti Tun Hussein Onn Malaysia (UTHM), Malaysia \\ ${ }^{2}$ Advanced Manufacturing and Materials Center (AMMC), ORICC, Universiti Tun Hussein Onn Malaysia(UTHM), \\ Malaysia \\ ${ }^{3}$ Faculty of Mechanical and Manufacturing, Universiti Tun Hussein Onn Malaysia (UTHM), Malaysia \\ ${ }^{4}$ Pulp and Paper Laboratory, Biomass Technology Programme, Forest Products Division, Forest Research Institute \\ Malaysia (FRIM)
}

\begin{abstract}
In recent years, there has been tremendous growth of interest in the utilization of non-wood based material to support the insufficient raw materials availability for the pulp and paper industry. Therefore, this study was conducted to investigate the characteristics of 120 gsm linerboard and corrugated medium paper made from unbeaten durian rinds chemimechanical (CMP) pulp. The linerboard and corrugated medium paper were prepared and tested according to Malaysian Standards / International Organization for Standardization (MS ISO) and Technical Association of the Pulp and Paper Industry (TAPPI) standard methods. Based on the burst index $\left(2.03 \mathrm{kPa} . \mathrm{m}^{2} / \mathrm{g}\right), \mathrm{RCT}(1.97 \mathrm{N.m} / \mathrm{g})$ and CMT $(129 \mathrm{~N})$, the linerboard and corrugated medium from CMP durian rind pulp have shown a good potential as an alternative raw material for papermaking and comparable with other types of wood and nonwood based papers as well as current commercial papers.
\end{abstract}

\section{Introduction}

Nowadays, insufficient supply of wood-based raw materials for packaging industries due to environmental issues leads to tremendous interest in the utilization of non-wood based materials in papermaking. In Malaysia, almost $50 \%$ of total paper consumption comes from packaging papers [1, 2]. The country is a net importer of pulp and paper in order to satisfy the domestic consumption [3]. Eighteen(18) out of 20 Malaysian paper mills utilize 95\% waste paper and old corrugated carton (OCC) as their main raw material, with the exception of Kimberly-Clark (M) Bhd. and Sabah Forest Industries that use $80 \%$ imported virgin pulp and $100 \%$ mixed tropical hardwood pulp, respectively [4]. In short, the paper and paperboard industries in Malaysia utilize imported virgin long-fiber pulp and secondary fibers, such as the old corrugated container (OCC) and waste papers to produce packaging papers [5]. In order to reduce the dependence on imported pulps, various researches have been conducted on the utilization of agricultural wastes as raw material alternatives for packaging paper such as kenaf [1, 2, 6], coir [5], oil palm empty fruit bunch [7, 8], Semantan bamboo [9] and oil

${ }^{\text {a }}$ Corresponding author : srizal@uthm.edu.my 
palm male flower spikes [10,11]. Malaysia has an abundance of agro waste materials which have not been fully utilized [12].

Malaysia is one of the major fresh and frozen durian exporters besides Thailand and Indonesia [1315]. In Malaysia, based on a study by Amid and Mirhosseini [16] stated that the rind constitutes in average about $45 \%$ for each mature fruit, Aditiya et al. [15] have calculated that durian rind waste generates about 133,688 to 171,303.9 metric tons from the year of 2006 until 2013 [15]. According to Ministry of Agriculture and Agro-based Industry Malaysia (MOA) [17], there were 376,565 metric tons of durian fruits were produced in 2014. Thus, massive amounts of the durian peels waste are disposed of, causing a severe problem in the community [18]. Therefore, the utilization of the durian rinds waste as pulp and paper alternative raw material would be beneficial. However, based on the authors' best knowledge there were limited research attentions and published works on the utilization of durian rinds waste as an alternative papermaking material.

The author previous study by Masrol, Ibrahim and Adnan [19] has successfully produced durian rinds pulp via chemi-mechanical pulping (CMP). In order to extend the study on utilizing durian rinds waste as packaging alternative raw material, this study was conducted to investigate the potential of durian rinds CMP pulp as linerboard and corrugated medium paper.

\section{Experimental}

\subsection{Raw material preparations}

Durian rinds were collected from a local durian flesh manufacturer at Batu Pahat, Johor, Malaysia. Only the rinds of D24 durian have been collected to ensure the accuracy and repeatability of results. Firstly, durian rinds were cleaned from the residual aril and dirt. Then, the cleaned durian rinds were sliced, spine removed, cubed and dried naturally according to a procedure developed by Masrol et al. [19]. Finally, the dried durian rinds were stored inside air-tight storage to prevent moisture and fungus infestation.

\subsection{Chemi-mechanical pulping process}

Durian rinds pulp was produced by a chemi-mechanical pulping process according to pulping conditions conducted by Masrol et al. [19]. Dried durian rinds were treated with $10 \%$ (based on raw material oven-dry (o.d.) weight) solution of Sodium Hydroxide $(\mathrm{NaOH})$ at room temperature for 2 hours. Then, the treated durian rinds were refined by Sprout-Waldron refiner mechanical pulping (RMP) machine to produce pulp. Refiner mechanical pulping (RMP) is preferred because of its low production, labor and capital costs [20]. After the RMP process, screening was carried out using PTI Sommerville Fractionators according to TAPPI T 275 standard with a slot size of $0.15 \mathrm{~mm}$. After the screening, a spin-dry Neng Shin extractor was used to remove excess water and the screened pulp was dispersed into smaller size using a Hobart mixer. Finally, durian rinds CMP pulps were sealed in polyethylene bags and stored inside chillers at a temperature of $6^{\circ} \mathrm{C}$ before laboratory hand sheets preparation.

\subsection{Laboratory hand sheet preparation}

Laboratory hand sheets with a grammage of $120 \pm 3 \mathrm{~g} / \mathrm{m}^{2}$ were produced from unbleached and unbeaten durian rinds chemi-mechanical pulp using a semi-automatic sheet machine (British Handsheet Machine) based on MS ISO 5269-1: 2007 "Pulps - Preparation of Laboratory Sheets for Physical Testing - Part 1: Conventional Sheet-Former Method (ISO 5269-1: 2005, IDT)". The hand sheets were dried and conditioned at $23 \pm 1{ }^{\circ} \mathrm{C}$ and $50 \pm 2.0 \%$ relative humidity (RH) according to TAPPI T 402 sp-03 "Standard Conditioning and Testing Atmospheres for Paper, Board, Pulp Handsheets and Related Products" and MS ISO 187: 2001 "Paper, Board and Pulps - Standard 
Atmosphere for Conditioning and Testing and Procedure for Monitoring the Atmosphere and Conditioning of samples (ISO 187: 1990, IDT)" for at least 24 hours before further evaluation.

\subsection{Characteristics' tests}

The characteristics' tests $(\mathrm{a}-\mathrm{h})$ listed in Table 1 were conducted according to ISO 5270: 2012 "Pulps Laboratory sheets determination of physical properties" with accordance to Malaysian Standards / International Organization for Standardization (MS ISO). The test for CMT, RCT and $\mathrm{Cobb}_{30}$ used for packaging grade paper (Table 1) were carried out in this study. All tests were performed in a controlled temperature and humidity environment as stipulated in TAPPI T 402 sp-03 "Standard Conditioning and Testing Atmospheres for Paper, Board, Pulp Handsheets and Related Products" and MS ISO 187: 2001 "Paper, Board and Pulps - Standard Atmosphere for Conditioning and Testing and Procedure for Monitoring the Atmosphere and Conditioning of samples (ISO 187: 1990, IDT)". The sampling was conducted according to TAPPI T400 sp-02 "Sampling and Accepting a Single Lot of Paper, Paperboard, Containerboard, or Related Product" and MS ISO 186: 2002, IDT "Paper and Board - Sampling to Determine Average Quality".

Table 1. Characteristics' tests list and standards

\begin{tabular}{|c|c|c|}
\hline No. & Test & MS ISO / TAPPI \\
\hline a. & Grammage & MS ISO 536: 2001: Paper and Board-Determination of Grammage \\
\hline b. & Thickness & $\begin{array}{l}\text { MS ISO 534: 2007, IDT: Paper and Board - Determination of Thickness, } \\
\text { Density and Specific Volume }\end{array}$ \\
\hline c. & Brightness & $\begin{array}{l}\text { MS ISO 2470-1: 2010: Paper, Board and Pulps - Measurement of Diffuse } \\
\text { Blue Reflectance Factor-Part 1: Indoor Daylight Conditions -ISO Brightness- } \\
\text { First revision (ISO 2470-1: 2009, IDT) }\end{array}$ \\
\hline d. & Opacity & $\begin{array}{l}\text { MS ISO 2471: 2010: Paper, Board and Pulps - Determination of Opacity } \\
\text { (Paper Backing) - Diffuse Reflectance Method - First revision (ISO 2471: } \\
\text { 2008, IDT) }\end{array}$ \\
\hline e. & Tensile & $\begin{array}{l}\text { MS ISO 1924-2: 2010: Paper and Board - Determination of Tensile } \\
\text { Properties - Part } 2 \text { - Constant Rate of Elongation Method - } 20 \mathrm{~mm} / \mathrm{min}- \\
\text { First revision (ISO 1924-2: 2008, IDT) }\end{array}$ \\
\hline f. & Tearing & $\begin{array}{l}\text { MS ISO 1974: 1999: Paper - Determination of Tearing Resistance - } \\
\text { Elmendorf Method - Second Revision (ISO 1974:1990, IDT) }\end{array}$ \\
\hline g. & Bursting & $\begin{array}{l}\text { MS ISO 2758: 2007: Paper-Determination of Bursting Strength } \\
\text { (ISO 2758: 2001, IDT) }\end{array}$ \\
\hline h. & Folding & MS ISO 5626: 1999: Paper - Determination of Folding Endurance \\
\hline i. & $\mathrm{RCT}$ & TAPPI T 818: Ring Crush of Paperboard \\
\hline $\mathrm{j}$. & CMT & TAPPI standard T 809 om-99: Flat crush of corrugating medium (CMT test) \\
\hline $\mathrm{k}$. & $\mathrm{Cobb}_{30}$ & MS ISO 535: 2001: Determination of water absorptiveness - Cobb test \\
\hline
\end{tabular}

\subsubsection{Ring crush test (RCT) and corrugated medium test (CMT)}

The ring crush test (RCT) can be defined as an edgewise compression strength test of corrugated boards which is intended to characterize a paperboard's resistance to crushing by in-plane compressive forces. RCT is used for test liner and other papers used in packaging manufacture [21]. The test specimen with a dimension of $12.7 \mathrm{~mm}$ width $\mathrm{x} 152.44 \mathrm{~mm}$ length is cut by a strip punch as shown in Figure 1a and inserted into the sample holder (Figure 1b). Samples were tested using the L $\& \mathrm{~W}$ Crush Tester to measure the compression force required before the test specimens buckle as shown in Figure 1c. 


\section{MATEC Web of Conferences}

CMT can be defined as a test to measure the flat compression strength of a laboratory fluted strip of a corrugating medium and can be used as a basis for judgment of fabrication efficiency. The CMT permits the evaluation of corrugating medium before it is fabricated into combined board [22]. The test specimen with the size of $12.7 \mathrm{~mm}$ wide $\mathrm{x} 152.4 \mathrm{~mm}$ long is cut by a special die cutter and formed into a flute shape using Concora Medium Fluter in Figure 2a. The rack and comb inside the fluter machine work to perfectly shape the sample into flute shape as shown in Figure $2 \mathrm{~b}$. Samples were tested using the same L \& W Crush Tester machine shown in Figure 1c.
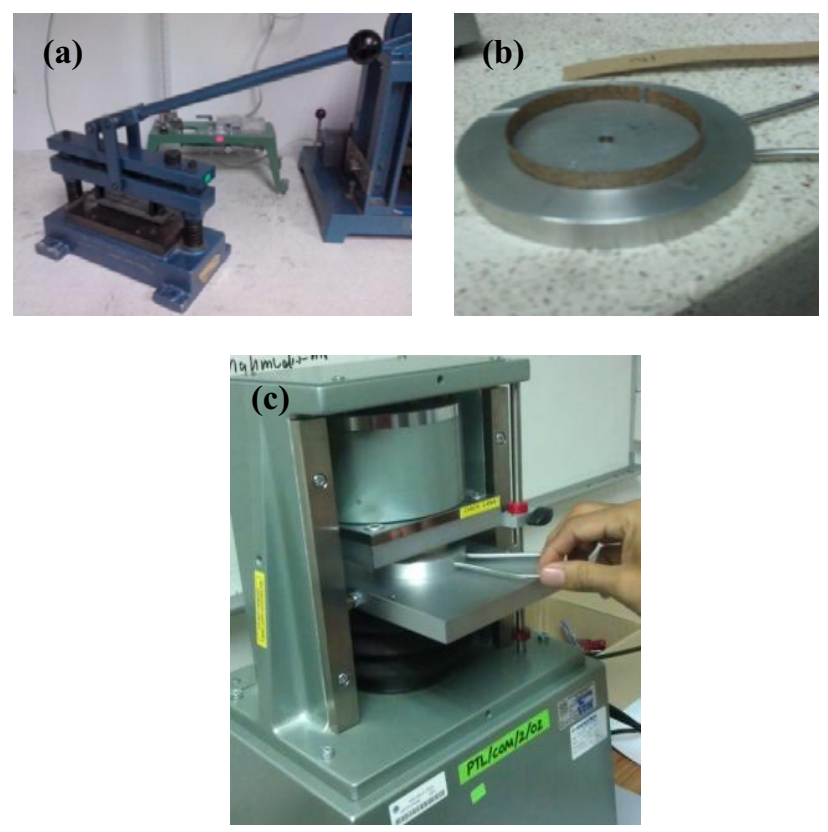

Figure 1. Ring crush test (RCT) procedure: (a) strip punch; (b) sample holder; and (c) L\&W crush tester

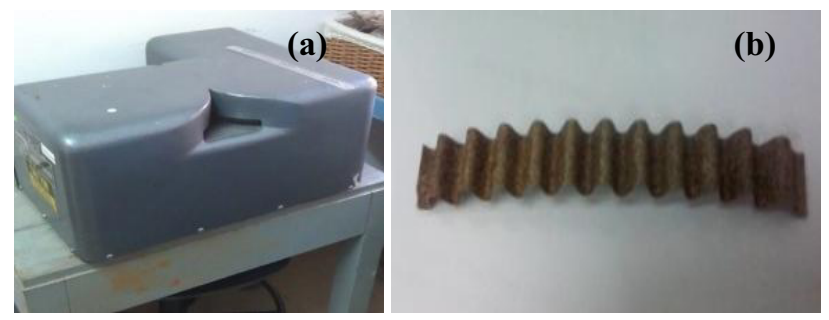

Figure 2. Corrugated medium test (CMT): (a) concora medium flutter; and (b) corrugated medium flute

\subsubsection{Water absorption test (Cobb ${ }_{30}$ test)}

The purpose of this method is to determine the quantity of water absorbed by a linerboard in a specified time. Distilled water is used for the test to avoid any substance factor that can affect the absorption characteristics of the paper tested. The weight of the sample is measured before and after the test (Figure 3a and Figure 3d). The samples were tested for water penetration for at $20 \pm 1$ seconds within $30 \pm 1$ seconds total test time as shown in Figure $3 \mathrm{c}$. 


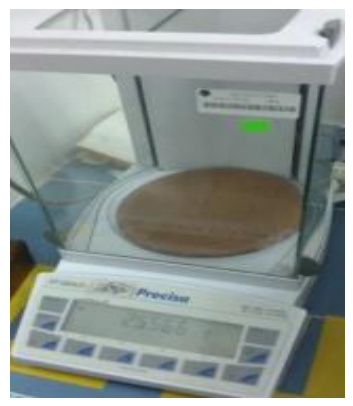

(a)

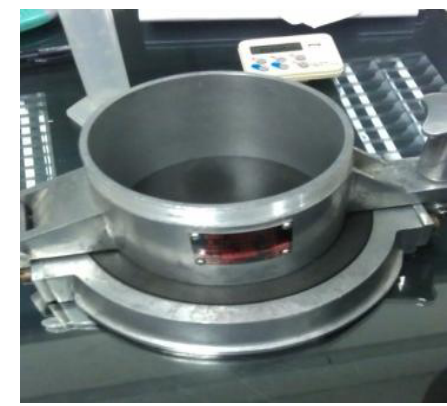

(b)

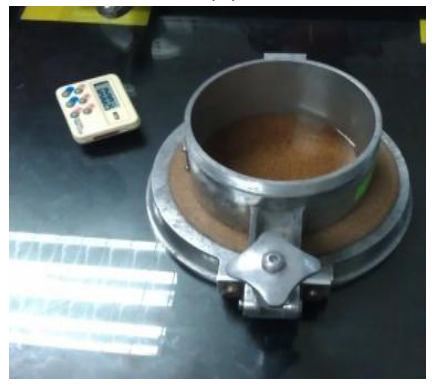

(c)

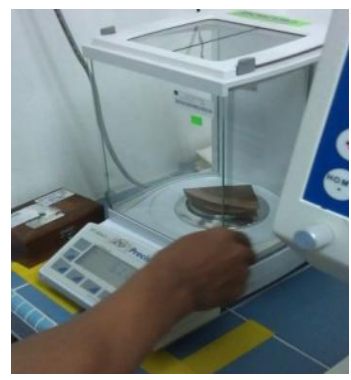

(d)

Figure 3. $\mathrm{COBB}_{30}$ test procedure: (a) weight before; (b) Cobb test device; (c) sample holder; and (d) weight after

\section{Results and Discussion}

\subsection{Laboratory hand sheet characteristics}

Table 2 shows the physical and optical characteristics of 120 gsm linerboard produced from durian rinds chemi-mechanical pulp (CMP). The number of folds for 120 gsm linerboard (37) was higher compared to 15 by previous 60 gsm paper [19]. For optical characteristics, ISO brightness (13.20\%) and opacity $(97.73 \%)$ are similar with Masrol et al. [19]. The result of $\mathrm{Cobb}_{30}$ test $\left(225 \mathrm{~g} / \mathrm{m}^{2}\right)$ shows that water penetrates durian rinds CMP linerboard too fast. This result could be improved by the addition of a sizing agent such as starch during the paper sheet preparation in the future.

Table 2. Physical and optical characteristics of durian rinds linerboard

\begin{tabular}{lc}
\hline Characteristics & Value \\
\hline Grammage $\left(\mathrm{g} / \mathrm{m}^{2}\right)$ & 122 \\
Apparent bulk density $\left(\mathrm{g} / \mathrm{cm}^{3}\right)$ & 0.73 \\
Double Fold, No & 37 \\
ISO Brightness (\%) & 13.20 \\
ISO Opacity $(\%)$ & 97.73 \\
Cobb $_{30}\left(\mathrm{~g} / \mathrm{m}^{2}\right)$ & 225 \\
\hline
\end{tabular}

\subsection{Paper mechanical properties comparison with other raw materials}

Table 3 shows the comparison of tensile, tear and burst indices between durian rinds CMP pulp and other types of materials reported by previous researchers. Results indicate that there is no significance difference in mechanical characteristics (tensile, tear and burst indices) between $120 \mathrm{gsm}$ and $60 \mathrm{gsm}$ reported by Masrol et al. [19]. Durian rinds unbeaten CMP pulp's tensile index is higher than empty 
fruit bunch (EFB) [8], Acacia mangium [8], Eucalyptus globulus [8], rapeseed [23], Semantan bamboo [24] and coir CMP [25]. For tear index, unbeaten durian rinds CMP recorded a higher value than Acacia mangium [8], Eucalyptus globulus [8] and rapeseed [23]. Durian rinds CMP also recorded a better burst index than empty fruit bunch (EFB) [8], Eucalyptus globulus [8], rapeseed [23], Semantan bamboo [24] and coir CMP [25]. The results show that durian rinds CMP is comparable with other types of raw materials for papermaking. However, mechanical treatments such as beating or refining is recommended for unbeaten durian rinds CMP pulp in order to enhance the pulp and paper characteristics $[5,11,24]$.

Table 3. Mechanical properties of durian rinds CMP compared with another types of linerboard

\begin{tabular}{|c|c|c|c|}
\hline Material & $\begin{array}{l}\text { Tensile Index } \\
\text { (N.m/g) }\end{array}$ & $\begin{array}{l}\text { Tear Index } \\
\left(\mathrm{mN} \cdot \mathrm{m}^{2} / \mathrm{g}\right)\end{array}$ & $\begin{array}{c}\text { Burst Index } \\
\left(\mathrm{kPa}^{2} \mathrm{~m}^{2} / \mathrm{g}\right)\end{array}$ \\
\hline Durian CMP & 36.48 & 6.72 & 2.03 \\
\hline Kenaf KHK[1] & 71.03 & 13.38 & 4.18 \\
\hline Kenaf KLK[1] & 78.84 & 15.11 & 5.12 \\
\hline Kenaf Bast[1] & 40.83 & 20.68 & 2.66 \\
\hline Kenaf Core[2] & 83.09 & 5.87 & 6.09 \\
\hline${ }^{\mathrm{b}}$ Kenaf KHK[2] & 78.21 & 14.35 & 5.21 \\
\hline${ }^{\mathrm{b}}$ Kenaf KLK[2] & 86.10 & 14.36 & 5.90 \\
\hline${ }^{\mathrm{b}}$ Kenaf Bast[2] & 72.47 & 23.95 & 4.70 \\
\hline${ }^{\mathrm{b}} \mathrm{OCC}[2]$ & 42.27 & 7.02 & 2.79 \\
\hline${ }^{\mathrm{b}} \mathrm{USWK}[2]$ & 95.18 & 12.49 & 7.23 \\
\hline${ }^{\mathrm{a}}$ Coir Soda-AQ[5] & 44.66 & 11.76 & 4.57 \\
\hline EFB[8] & 21.37 & 5.85 & 1.41 \\
\hline Acacia mangium $[8]$ & 2.53 & 3.28 & 6.76 \\
\hline Eucalyptus globulus[8] & 24.84 & 4.33 & 0.13 \\
\hline Rapeseed[23] & 25.57 & 3.70 & 1.24 \\
\hline${ }^{\mathrm{a} S e m a n t a n}$ bamboo[24] & 32.54 & 13.45 & 1.54 \\
\hline Coir CMP[25] & 18.33 & 7.05 & 1.85 \\
\hline Bagasse[26] & 43.60 & 5.47 & 2.63 \\
\hline
\end{tabular}

$\mathrm{a}=$ optimum pulp; $\mathrm{b}$ : beaten pulp

\subsection{Comparison of burst index, RCT and CMT with other types of paper}

Table 4 shows that RCT results of durian rinds 120 gsm linerboard and corrugated medium made from CMP pulp are comparable with other paper types and commercial linerboards.

Linerboards with a high apparent density indicates a good bonding ability between fibers during paper formation [5]. In this study, the durian rinds linerboard produced has an apparent density of 0.73 $\mathrm{g} / \mathrm{cm}^{3}$ which is similar with other non-wood based and commercial linerboards (Table 4). Apparent density is one of the most significant properties of paper and influences almost all mechanical, physical, and electrical properties [8].

In industrial practices, burst strength indirectly measures the internal resistance of corrugated box container to any kind of force applied [5]. The burst index of durian rinds CMP linerboard recorded a value of $2.03 \mathrm{kPa} \cdot \mathrm{m}^{2} / \mathrm{g}$ which is higher than some commercial linerboards' minimum requirement such as GSPP IL3, GSPP IL4, GSPP IL5, GSPP IL6, Pascorp IL1, Pascorp IL4, Pascorp IL4 and Pascorp IL6 reported by Main et al. [5]. The burst index for durian rinds linerboard is also higher than commercial scale linerboards developed by Rushdan [8] except for SANYEN 6 and SANYEN 13.

Unbeaten durian rinds CMP linerboard recorded RCT value of $1.58 \mathrm{kN} / \mathrm{m}$ and $1.97 \mathrm{~N} . \mathrm{m}^{2} / \mathrm{g}$ for RCT index. For RCT index, durian rinds CMP linerboard recorded a higher value than the minimum requirement of commercial linerboards by GSPP and Pascorp as reported by Main et al. [5]. RCT of 
durian rinds CMP linerboard is higher than Kenaf bast [1], OCC [2] and overall commercial scale linerboards developed by Rushdan et al. [8].

Durian rinds CMP linerboard CMT (129N) value is higher than coir [5, 27] and OCC [28] linerboards. The CMT index of durian rinds linerboard $(1.06 \mathrm{N.m} / \mathrm{g})$ is also slightly higher than Semantan Bamboo [9], Kenaf [9] as well as commercial scale SANYEN 40 linerboard [8]; and a bit similar with CF Mischantus pulp [29].

Therefore, based on the result of burst index, RCT and CMT, durian rinds CMP pulp has shown a good potential as an alternative material for linerboard and corrugated medium

\section{Conclusion}

In this study, durian rinds chemi-mechanical pulp (CMP) linerboard and corrugated medium flutes were successfully produced and analyzed. The results demonstrated that durian rinds chemimechanical pulp is suitable for linerboard and corrugated medium applications. The properties of durian rinds CMP linerboard and corrugated medium produced are comparable to other types of wood and non-wood raw materials as well as commercial linerboards specifications produced in Malaysia. However, continuous improvement is necessary in order to achieve optimum quality for CMP pulp produced from durian rinds. In future, optimization of CMP pulping variables (active alkali percentage, digestion time and beating revolutions) is required to obtain the optimum pulp that can produce durian rinds CMP paper with the best characteristics and quality. Furthermore, the addition sizing agents should be considered to improve durian rinds linerboard water absorptiveness. Beating or refining process also needs to be applied to enhance the characteristics of the CMP durian rinds pulp and paper. The findings of this research would be beneficial to the pulp and paper industry as well as the agriculture, namely durian based, industry.

Table 4. Characteristics of durian rinds CMP compared to various type linerboards and corrugated mediums

\begin{tabular}{|c|c|c|c|c|c|c|c|c|}
\hline Material & $\begin{array}{c}\mathbf{G} \\
\left(\mathrm{g} / \mathbf{m}^{2}\right)\end{array}$ & $\begin{array}{c}\text { BI } \\
\left(\mathrm{kPa} \cdot \mathrm{m}^{2} / \mathrm{g}\right)\end{array}$ & $\begin{array}{c}\text { Bulk } \\
\left(\mathrm{cm}^{3} / \mathrm{g}\right)\end{array}$ & $\begin{array}{c}\text { Bulk } \\
\left(\mathrm{g} / \mathrm{cm}^{3}\right)\end{array}$ & $\begin{array}{c}\text { RCT } \\
\left(\mathbf{N} . \mathrm{m}^{2} / \mathbf{g}\right)\end{array}$ & $\begin{array}{c}\text { RCT } \\
(\mathrm{kN} / \mathrm{m})\end{array}$ & $\begin{array}{c}\text { CMT } \\
\text { (N) }\end{array}$ & $\begin{array}{c}\text { CMT } \\
\left(\mathrm{N} . \mathrm{m}^{2} / \mathrm{g}\right)\end{array}$ \\
\hline $100 \%$ Durian & 122 & 2.03 & 1.38 & 0.73 & 1.97 & 1.58 & 129 & 1.06 \\
\hline Kenaf core[1] & 150 & 4.18 & - & 0.716 & - & 2.87 & - & - \\
\hline Kenaf KHK[1] & 150 & 5.12 & - & 0.590 & - & 1.85 & - & - \\
\hline Kenaf KLK[1] & 150 & 2.66 & - & 0.620 & - & 2.25 & - & - \\
\hline Kenaf bast[1] & 150 & 6.09 & - & 0.502 & - & 1.43 & - & - \\
\hline${ }^{\mathrm{b}}$ Kenaf KHK[2] & 150 & 5.21 & - & 0.651 & - & 2.25 & - & - \\
\hline${ }^{\mathrm{b}}$ Kenaf KLK[2] & 150 & 5.90 & - & 0.672 & - & 2.68 & - & - \\
\hline${ }^{\mathrm{b}}$ Kenaf bast[2] & 150 & 4.70 & - & 0.594 & - & 2.61 & - & - \\
\hline${ }^{\mathrm{b}} \mathrm{OCC}[2]$ & 150 & 2.79 & - & 0.533 & - & 1.32 & - & - \\
\hline${ }^{\mathrm{b}}$ OSWK[2] & 150 & 7.23 & - & 0.723 & - & 3.14 & - & - \\
\hline Coir[5][27] & 120 & 4.57 & - & 0.71 & 1.76 & - & 87 & - \\
\hline GSPP IKL1[5] & 150 & $\geq 3.12$ & - & 0.68 & $\geq 1.39$ & - & - & - \\
\hline GSPP IKL2[5] & 175 & $\geq 3.12$ & - & 0.73 & $\geq 1.47$ & - & - & - \\
\hline GSPP IKL3[5] & 275 & $\geq 2.85$ & - & 0.79 & $\geq 1.71$ & - & - & - \\
\hline GSPP IKL4[5] & 165 & $\geq 2.70$ & - & 0.72 & $\geq 1.58$ & - & - & - \\
\hline GSPP IL1[5] & 150 & $\geq 2.09$ & - & 0.68 & $\geq 1.13$ & - & - & - \\
\hline GSPP IL2[5] & 180 & $\geq 2.09$ & - & 0.72 & $\geq 1.27$ & - & - & - \\
\hline GSPP IL3[5] & 275 & $\geq 1.80$ & - & 0.79 & $\geq 1.38$ & - & - & - \\
\hline GSPP IL4[5] & 140 & $\geq 1.80$ & - & 0.79 & $\geq 1.04$ & - & - & - \\
\hline GSPP IL5[5] & 170 & $\geq 1.80$ & - & 0.74 & $\geq 1.03$ & - & - & - \\
\hline GSPP IL6[5] & 250 & $\geq 1.80$ & - & 0.81 & $\geq 1.03$ & - & - & - \\
\hline Pascorp IL1[5] & 135 & $\geq 2.00$ & - & 0.71 & $\geq 1.11$ & - & - & - \\
\hline Pascorp IL2 [5] & 140 & $\geq 2.09$ & - & 0.70 & $\geq 1.14$ & - & - & - \\
\hline Pascorp IL3 [5] & 150 & $\geq 2.09$ & - & 0.71 & $\geq 1.13$ & - & - & - \\
\hline Pascorp IL4[5] & 165 & $\geq 2.00$ & - & 0.72 & $\geq 1.21$ & - & - & - \\
\hline Pascorp IL5[5] & 170 & $\geq 2.00$ & - & 0.71 & $\geq 1.26$ & - & - & - \\
\hline
\end{tabular}




\begin{tabular}{|c|c|c|c|c|c|c|c|c|}
\hline Pascorp IL6[5] & 175 & $\geq 2.00$ & - & 0.70 & $\geq 1.30$ & - & - & - \\
\hline SANYEN 6[8] & 123.58 & 2.54 & 1.49 & - & - & 1.4 & - & 1.6 \\
\hline SANYEN 13[8] & 121.90 & 2.30 & 1.51 & - & - & 1.5 & - & 1.5 \\
\hline SANYEN 20[8] & 118.39 & 1.92 & 1.55 & - & - & 1.4 & - & 1.5 \\
\hline SANYEN 26[8] & 118.77 & 1.95 & 1.58 & - & - & 1.3 & - & 1.6 \\
\hline SANYEN 40[8] & 121.45 & 1.55 & 1.56 & - & - & 1.1 & - & 1.0 \\
\hline SANYEN 50[8] & 114.87 & 1.59 & 1.87 & - & - & 1.2 & - & 1.3 \\
\hline TRI025[8] & 122.53 & 1.71 & 1.93 & - & - & 1.2 & - & 1.2 \\
\hline TRIO45[8] & 124.62 & 1.67 & 1.82 & - & - & 1.1 & - & 1.2 \\
\hline TRIO50[8] & 122.55 & 1.75 & 1.76 & - & - & 1.0 & - & 1.2 \\
\hline $\begin{array}{l}\text { PASCORP20 }[8 \\
\text { ] }\end{array}$ & 113.21 & 1.40 & 1.68 & - & - & 1.1 & - & 1.3 \\
\hline PASCORP25[8 & 112.05 & 1.25 & 1.82 & - & - & 1.1 & - & 1.3 \\
\hline $\begin{array}{l}100 \% \text { Old } \\
\text { OCC }[8]\end{array}$ & 121.90 & 1.54 & 1.79 & - & - & 1.3 & - & 1.3 \\
\hline Bamboo[9] & 120 & & - & - & - & - & - & 1.04 \\
\hline Softwood[9] & 120 & & - & - & - & - & - & 1.78 \\
\hline Kenaf[9] & 120 & & - & - & - & - & - & 0.98 \\
\hline $\begin{array}{l}\text { Cardoon } \\
\text { pulp[21] }\end{array}$ & 130 & & - & - & - & - & 235 & - \\
\hline $\begin{array}{l}\text { Waste paper } \\
\text { pulp[21] }\end{array}$ & 130 & & - & - & - & - & 145 & - \\
\hline $\begin{array}{l}\text { Hardwood } \\
\text { NSSC[21] }\end{array}$ & 130 & & - & - & - & - & 200 & - \\
\hline $\begin{array}{l}\text { Wheat } \\
\text { straw[28] }\end{array}$ & 120 & & 5.7 & - & - & - & 330 & - \\
\hline OCC $[28]$ & 120 & & 1.3 & - & - & - & 103 & - \\
\hline $\begin{array}{l}\text { Wheat } \\
\text { Straw+OCC }[28 \\
\text { ] }\end{array}$ & 120 & & 4.0 & - & - & - & 260 & - \\
\hline $\begin{array}{l}\text { Semi- } \\
\text { Chemical[30] }\end{array}$ & $\begin{array}{l}151- \\
172\end{array}$ & & - & - & - & - & 421 & - \\
\hline $\begin{array}{l}\text { Recycled } \\
\text { medium[30] }\end{array}$ & $91-111$ & & - & - & - & - & 187 & - \\
\hline $\begin{array}{l}\text { Mischantus } \\
\text { pulp[29] }\end{array}$ & - & 2.3 & - & - & - & - & - & 1.54 \\
\hline $\begin{array}{l}\text { CF Mischantus } \\
\text { pulp[29] }\end{array}$ & - & 1.67 & - & - & - & - & - & 1.065 \\
\hline
\end{tabular}

\section{Acknowledgements}

The authors would like to thank Universiti Tun Hussein Onn Malaysia for funding this project under UTHM Short Term Grant (STG Vot. 1333) and Ministry of Higher Education Malaysia under SLAI scholarship scheme. The authors would also like to acknowledge Pulp and Paper Laboratory, Biomass Technology Programme, Forest Products Division, Forest Research Institute Malaysia for research facilities and support

\section{References}

1. A. A. Mossello, J. Harun, H. Resalati, R. Ibrahim, P. Md Tahir, S. R. Fallah Shamsi, and A. Z. Mohamed, Soda-anthraquinone pulp from Malaysian cultivated kenaf for linerboard production. BioResources. 5(3), $1542-1553$ (2010)

2. A. A. Mossello, J. Harun, R. Ibrahim, H. Resalati, S. R. Fallah Shamsi, P. Md Tahir, and M. N. Mohad Yusof, Evaluation of linerboard properties from Malaysian cultivated kenaf soda-anthraquinone pulps 
versus commercial pulps. BioResources. 5(3), 1595-1604 (2010).

3. P. Singh, O. Sulaiman, R. Hashim, L. C. Peng, and R. S. Singh, Using biomass residues from oil palm industry as a raw material for pulp and paper industry: potential benefits and threat to the environment. Environment, Development and Sustainability, 15(2), 367-383 (2013).

4. L. Jasmani, S. Mahmudin, and R. Ibrahim, Recycled paper strengthened with Kenaf. FRIM in Focus: Waste to Wealth (Forest Research Institute Malaysia, Kepong, Selangor, p. 10, Sep-2009).

5. N. M. Main, R. A Talib, R. Ibrahim, R. Abdul Rahman, and A. Z. Mohamed, Linerboard made from sodaanthraquinone (Soda-AQ) treated coconut coir fiber and effect of pulp beating. BioResources. 10(4), 6975$6992 \quad$ (2015).

6. A. A. Mossello, J. Harun, H. Resalati, R. Ibrahim, S. R. Fallah Shamsi, and P. Md Tahir, New approach to use of kenaf for paper and paperboard production. BioResources 5(4), 2112-2122 (2010).

7. R. Ibrahim, Structural, mechanical and optical properties of recycled paper blended with oil palm empty fruit bunch. Journal of Oil Palm Research. 15(2), 28-34 (2003).

8. I. Rushdan, J. Latifah, W. K. Hoi, and M. Y. Mohd Nor, Commercial-scale production of soda pulp and medium paper from oil palm empty fruit bunches. Journal of Tropical Forest Science. 19(3), 121-126 (2007).

9. N. H. Mohd Hassan, S. Muhammed, and R. Ibrahim, Properties of corrugated paper from recycled paper blended with Semantan bamboo. Australian Journal of Basic and Applied Sciences. 8(9), 113-117 (2015).

10. S. R. Masrol, M. H. I. Ibrahim, S. Adnan, M. S. S. Amir Shah, N. M. Main, M. F. Esa, and M. H. Othman, Soda Anthraquinone pulping of oil palm male flower spikes. Applied Mechanics and Materials. 660, 373377 (2014).

11. S. R. Masrol, M. H. I. Ibrahim, S. Adnan, M. S. S. Amir Shah, N. M. Main, M. F. Esa, and M. H. Othman, Effect of beating process to soda anthraquinone pulp of oil palm male flower spikes fibre. Applied Mechanics and Materials. 773-774, 158-162 (2015).

12. Daud, Z., Mohd Hatta, M. Z., Mohd Kassim, A. S. and Aripin Mohd, A. Suitability of Malaysia's pineapple leaf and napier grass as a fiber substitution for paper making industry, EnCon 2013, $6^{\text {th }}$ Engineering Conference, "Energy and Enviroment". Kuching, Sarawak. 2-4 July (2013).

13. S. Hokputsa, W. Gerddit, S. Pongsamart, K. Inngjerdingen, T. Heinze, A. Koschella, S. E. Harding, and B. S. Paulsen, Water-soluble polysaccharides with pharmaceutical importance from Durian rinds (Durio zibethinus Murr.): isolation, fractionation, characterisation and bioactivity. Carbohydrate Polymers. 56(4), 471-481 (2004).

14. M. Unhasirikul, N. Naranong, and W. Narkrugsa, Reducing sugar production from durian peel by hydrochloric acid hydrolysis. World Academy of Science, Engineering and Technology. 6(9), 394-399 (2012).

15. H. B. Aditiya, W. T. Chong, T. M. I. Mahlia, A. H. Sebayang, M. A. Berawi, and H. Nur, Second generation bioethanol potential from selected Malaysia's biodiversity biomasses: A review. Waste Management, 47(Part A), 46-61 (2016).

16. B. T. Amid and H. Mirhosseini, "Optimisation of aqueous extraction of gum from durian (Durio zibethinus) seed: A potential, low cost source of hydrocolloid. Food Chemistry, 132(3), 1258-1268 (2012).

17. Ministry of Agriculture and Agro-Based Industry Malaysia, Agrofood Statistics 2014 (Information Management and Statistics Section, Policy and Strategic Planning Division, Putrajaya, 2015).

18. B. H. Hameed and H. Hakimi, Utilization of durian (Durio zibethinus Murray) peel as low cost sorbent for the removal of acid dye from aqueous solutions. Biochemical Engineering Journal. 39(2), 338-343 (2008).

19. S. R. Masrol, M. H. I. Ibrahim, and S. Adnan, Chemi-mechanical pulping of durian rinds. Procedia Manufacturing. 2, 171-180 (2015).

20. R. Ibrahim, Moulded products from oil palm pulp. FRIM in Focus: Waste to Wealth. (Forest Research Institute Malaysia, Kepong, Selangor, p. 11, Sep-2009).

21. S. Abrantes, M. E. Amaral, A. P. Costa, and A. P. Duarte, Cynara cardunculus L. alkaline pulps: alternatives fibres for paper and paperboard production. Bioresource Technoloy. 98(15), 2873-2878 (2007).

22. A. Ghasemian, M. Ghaffari, and A. Ashori, Strength-enhancing effect of cationic starch on mixed recycled and virgin pulps. Carbohydrate Polymers. 87, 1269-1274 (2012).

23. I. Gonzalez, M. Alcalá, G. Arbat, F. Vilaseca, and P. Mutjè, Suitability of rapeseed chemithermomechanical pulp as raw material in papermaking. BioResources. 8(2), 1697-1708 (2013).

24. N. H. Mohd Hassan, S. Muhammed, and R. Ibrahim, Properties of Gigantochloa scortechinii paper enhancement by beating revolution. Journal of Tropical Resources and Sustainable Science. 2, 59-67 (2014).

25. S. Mohamad Jani and I. Rushdan, Effect of bleaching on coir fibre pulp and paper properties. Journal of Tropical Agricuture and Food Science. 42(1), 51-61 (2014). 


\section{MATEC Web of Conferences}

26. P. Sheikhi, G. Asadpour, S. Zabihzadeh, and N. Amoee, An optimum mixture of virgin bagasse pulp and recycled pulp (OCC) for manufacturing fluting paper. Bioresources. 8(4), 5871-5883 (2013).

27. N. M. Main, R. A Talib, R. Abdul Rahman, A. Z. Mohamed, R. Ibrahim, and S. Adnan, Effect of amphoteric and cationic polyacrylamide on the structural and strength properties of coir paper. Procedia Manufacturing. 2, 28-34 (2015).

28. F. Sarkhosha and T. Mohammad, Soda-AQ pulping of wheat straw and its blending effect on old corrugated cardboard (OCC) pulp properties. Tappsa Journal. March, 35-39 (2009).

29. F. Marín, J. L. Sánchez, J. Arauzo, R. Fuertes, and A. Gonzalo, Semichemical pulping of Miscanthus giganteus. Effect of pulping conditions on some pulp and paper properties. Bioresource Technology. 100(17), 3933-3940 (2009).

30. S. Adamopoulos, E. Martinez, and D. Ramirez, Characterization of packaging grade papers from recycled raw materials through the study of fibre morphology and composition. Global NEST Journal. 9(1), 20-28 (2007). 